\title{
Oliver Dyma
}

\section{Die Wallfahrt zum Zweiten Tempel}

\author{
Untersuchungen zur Entwicklung der Wallfahrtsfeste in vorhasmonäischer Zeit
}

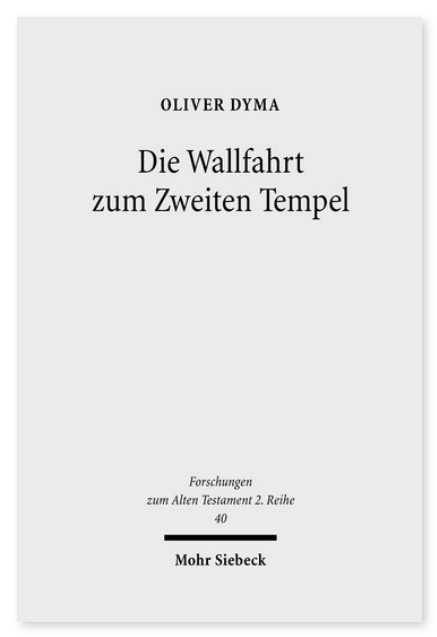

2009. XIV, 393 Seiten. FAT II 40

ISBN 978-3-16-151138-7

DOI 10.1628/978-3-16-151138-7

eBook PDF $94,00 €$

ISBN 978-3-16-149772-8

fadengeheftete Broschur $94,00 €$
Die heutige Sicht auf die großen Wallfahrtsfeste Pesach, Wochen- und Laubhüttenfest ist vor allem durch die Darstellungen im Neuen Testament, bei Josephus und in verschiedenen rabbinischen Texten geprägt. Oliver Dyma geht der Frage nach, ab wann man mit großen Wallfahrten nach Jerusalem mit Teilnehmern aus aller Welt rechnen kann. Hierzu analysiert er zunächst die sogenannten Kultkalender als normative Grundlage (Ex 23; Ex 34; Dtn 16; Lev 23; Num 28f.). Anschließend untersucht er die fiktionalen Darstellungen der zwei großen Pesachfeiern in den Chronikbüchern (2 Chr 30 und 35) sowie die fiktiven Erinnerungen an die Wallfahrten im Buch Tobit. Hierbei liegt der Schwerpunkt auf der Frage, welche historischen Rückschlüsse diese Texte für die Zeit ihrer Abfassung zulassen. In beiden Werken liegt ein besonderer Fokus auf den Wallfahrern aus dem Gebiet des ehemaligen Nordreiches, jedoch mit unterschiedlicher Akzentsetzung, was auf eine veränderte Wallfahrtspraxis hindeutet. Die sogenannten Wallfahrtspsalmen (Ps 120-134) erweisen sich schließlich als historisch kaum auswertbare Quellen. In der Zusammenschau zeigt sich, dass man vor der Zeit der Hasmonäer kaum mit einem großen Wallfahrtsbetrieb am Jerusalemer Tempel rechnen kann. Durch eine Analyse verschiedener Termini, die sonst dafür in Anschlag gebracht werden, zeigt Oliver Dyma, dass von einer spezifischen Wallfahrtsterminologie im Alten Testament nicht die Rede sein kann. Abschließend ordnet er die gewonnenen Erkenntnisse historisch ein und wirft einen Blick auf die weitere Entwicklung.

Oliver Dyma Geboren 1972; 1993-2000 Studium der Kath. Theologie in Tübingen, 2004 in Jerusalem; seit 2000 Assistent am Lehrstuhl für Altes Testament der Kath.-Theol. Fakultät in Tübingen.
Jetzt bestellen:

https://mohrsiebeck.com/buch/die-wallfahrt-zum-zweiten-tempel-9783161511387?no_cache=1

order@mohrsiebeck.com

Telefon: +49 (0)7071-923-17

Telefax: +49 (0)7071-51104 